\title{
Eliciting Incoming Engineering Students' Images of Engineering and Engi- neers at Two Mexican Institutions
}

\author{
Miss Caridad Cruz López, Universidad de las Américas, Puebla. \\ Prof. Aída Hernández Hernández, Universidad Politécnica de Tlaxcala
}

Aída Hernández Hernández is a Science, Engineering, and Technology Education Ph.D. student at Universidad de las Américas Puebla in Mexico. She teaches industrial engineering related courses at Universidad Politécnica de Tlaxcala. Her research interests include design of experiments, transfer of learning from schools to the workplace, and creating effective learning environments.

Prof. Aurelio Lopez-Malo, Universidad de las Americas Puebla

Dr. Enrique Palou, Universidad de las Americas Puebla

Professor Palou is director of the Center for Science, Engineering, and Technology Education in the Department of Chemical, Food, and Environmental Engineering at Universidad de las Americas Puebla in Mexico. He teaches engineering, food science, and education related courses. His research interests include emerging technologies for food processing, creating effective learning environments, using tablet PCs and associated technologies to enhance the development of 21 st century expertise in engineering students, and building rigorous research capacity in science, engineering and technology education. 


\title{
Eliciting Incoming Engineering Students' Images of Engineering and Engineers at Two Mexican Institutions
}

\begin{abstract}
In general, Mexican students have an incomplete understanding of engineers and engineering as a profession ${ }^{1,2}$. Images shape the way individuals view the world, thus, eliciting and understanding the images incoming engineering students have of engineering and what engineers do is extremely important in order to develop programs and adapt first-semester engineering curricula.
\end{abstract}

In this study, data were collected using the Draw an Engineer (DAE) test ${ }^{1-9}$ followed up by unstructured informal interviews. The 124 incoming engineering students participating in the study were given the DAE test at the beginning of their first day of classes, one group in the state of Puebla ( 32 participants, $\approx 40 \%$ men at a small private university) and the other in the state of Tlaxcala (92 participants, $\approx 70 \%$ men at a medium-size public polytechnic), 20 miles apart. The purpose of the DAE test was to determine individual conceptions of engineering and what engineers do as well as to make a comparison between incoming engineering students' conceptions from two Mexican states. Students were given 10 min to draw an engineer (previously they were asked to close their eyes and imagine an engineer at work) and then 10-15 min to answer three question prompts related to what they had drawn: 1) Describe what the engineer is doing in your drawing. Write at least two sentences. 2) List at least three words/phrases that come to mind when you think of an engineer. 3) What kinds of things do you think an engineer does? Study facilitators were careful not to talk about engineers or engineering during the administration of the DAE test. Facilitators offered help to clarify directions and question prompts, but they did not offer any ideas or assistance that would influence students' original conceptions of engineers or engineering. Twenty-eight informal interviews (which were videotaped) were performed after the DAE test and consisted of one-on-one discussions between a facilitator and students ( 8 from Puebla and 20 from Tlaxcala) to further investigate reasoning's behind his/her drawing and responses.

The drawings and open-ended responses were analyzed following an inductive data analysis approach. Three researchers were involved in the analysis process, which began with open coding because there were no pre-determined categories. Four main categories emerged to describe the data: 1) engineers in action, 2) characteristics of an engineer, 3) gender, and 4) work context. Even though the female participants (46) in this study were more than one third of the participants, close to $70 \%$ of incoming engineering students in this study perceived engineers as male individuals. Interviews supported main findings while helping researchers gain insight into individual reasoning behind the 28 interviewed students' drawings and answers. Outcomes from this study confirm that cultural models to which humans are exposed can contribute significantly to their mental schema ${ }^{10}$. 


\section{Introduction}

Mexico is one of the countries with the largest percentages of students performing below the baseline Proficiency Level 2 in mathematics and sciences among the Organisation for Economic Co-operation and Development (OECD) nations ${ }^{11}$. Given the crisis that Mexico faces in mathematics and science education in the P-12 levels, Universidad de las Américas Puebla started a research program to develop solutions to help overcome this situation. This investigation is part of a broader project funded by the Campeche State Council for Science and Technology (Consejo Estatal de Investigación Cientifica y Desarrollo Tecnológico de Campeche). Its goal is to promote an early approach to engineering and science among the student population at the upper elementary, middle and high school levels of the State of Campeche by creating high quality learning environments that promote interactive classrooms and contribute to a better understanding of science and mathematics while promoting careers in science, engineering and technology ${ }^{12}$.

In general, Mexican teachers and students have an incomplete understanding of engineers and engineering as a profession ${ }^{1,2,12}$. Images shape the way individuals view the world ${ }^{13}$, thus, eliciting and understanding the image students have of engineers and engineering is extremely important in order to develop programs and curricula that encourage engineering teaching and learning at the P-12 school levels ${ }^{1-9,12}$.

Subject-produced drawings offer a simple and unique way for researchers to assess individual conceptions. These individual-produced drawings offer a window into human sense making that is often beyond description using mere words ${ }^{6}$. Psychologists, scientists, sociologists, anthropologists, and education researchers, among others have used and continue to use subject-produced drawings in their research. In the 1950s, the famous anthropologist, Margaret Mead, asked US students to draw pictures of scientists" ${ }^{14}$. The "Draw a Scientist (DAS) test" has been widely used to assess students' attitudes about scientists ${ }^{15}$, even with Mexican students ${ }^{16}$. To help assess students' ideas about engineering a "Draw an Engineer test" was developed ${ }^{3,13,17}$ derived from the DAS test.

\section{Methodology}

The purpose of this study was to determine individual conceptions of engineering and what engineers do as well as to make a comparison between Puebla and Tlaxcala incoming engineering students' conceptions. The data collection was performed using a modified DAE test $^{3,13,17}$, followed up by informal unstructured interviews. The 124 incoming engineering students participating in the study (Table 1) were given the DAE test at the beginning of their first day of classes, one group in the state of Puebla (32 participants at a small top notch private research university) and the other in the state of Tlaxcala (92 participants at a medium-size public polytechnic), 20 miles apart. The purpose of the DAE test was to determine individual conceptions of engineering and what engineers do as well as to make a comparison between incoming engineering students' conceptions from two Mexican states. It is worth mentioning that in general, students from the two studied institutions are also from 
two distinctive socioeconomic groups. The majority of Tlaxcala students are from the lower middle class (several of them being first-generation students) while most students from Puebla are from the higher middle class of Mexico, mainly with both parents having at least an undergraduate degree.

Students were given 10 min to draw an engineer (previously they were asked to close their eyes and imagine an engineer at work) and then 10-15 min to answer three question prompts related to what they had drawn: 1) Describe what the engineer is doing in your drawing. Write at least two sentences. 2) List at least three words/phrases that come to mind when you think of an engineer. 3) What kinds of things do you think an engineer does? Study facilitators were careful not to talk about engineers or engineering during the administration of the DAE test. Facilitators offered help to clarify directions and question prompts, but they did not offer any ideas or assistance that would influence students' original conceptions of engineers or engineering. It is worth noting that Spanish language places nouns into gender classes; therefore, the instructions mentioned both a male (ingeniero) and a female (ingeniera) engineer to ensure gender neutrality in the test directions ${ }^{1,2,12}$. Twenty-eight informal interviews (which were videotaped) were performed after the DAE test and consisted of one-on-one discussions between a facilitator and students ( 8 from Puebla and 20 from Tlaxcala) to further investigate reasoning's behind his/her drawing and responses.

Studied groups were randomly selected with the consent of administrators, teachers, and students. Table 1 displays the percentages of participation taking into account gender.

Table 1. Participants by gender

\begin{tabular}{|c|c|c|}
\hline PARTICIPANTS & $\begin{array}{c}\text { PUBLIC } \\
\text { UNIVERSITY }\end{array}$ & $\begin{array}{c}\text { PRIVATE } \\
\text { UNIVERSITY }\end{array}$ \\
\hline FEMALE & $30.44 \%$ & $59.37 \%$ \\
\hline MALE & $69.56 \%$ & $40.63 \%$ \\
\hline
\end{tabular}

Drawings and open-ended responses were analyzed by three researchers (i.e., the last author and two doctoral students, which are the first two authors). Following the procedure described by Oware et $a l .{ }^{18}$, an inductive data analysis approach was utilized to code the drawings and written responses. After reading and re-reading the questionnaire responses and discussing their impressions of the entire data set, the researchers created a coding scheme that included four main categories to describe the data. Using this coding scheme, researchers coded each participant's response at the same time ${ }^{12}$.

\section{Results and discussion}

Four main categories emerged to describe the data: 1) gender, 2) engineers in action, 3) characteristics of an engineer, and 4) work context. With regards to gender, students' responses were classified into one of three categories (i.e., female engineer, male engineer, or 
unknown-gender engineer) according to the characteristics depicted in their drawings as previously reported $^{1,2,12}$. Pictorial representations were categorized observing stereotypical features associated to a specific gender; for instance, a dress or skirt was associated to a female engineer as well as drawings with more feminine traits (such as long hair with womanlike volume, the use of color in lips, or long eyelashes) and/or characteristic female form of the body (noting the hip, waist, and/or bust). Drawing descriptions also helped to figure out the characters' gender. Furthermore, some participants made explicit the gender of their character using the Spanish nouns ingeniera or ingeniero for a female or male engineer, respectively. In those cases with no clear indication of a specific gender, characters were coded as unknown-gender (both/neutral figure) engineers.

Even though the female participants (46) in this study were more than one third of the participants, the majority (69\%) of the drawings depicted a male engineer at work, while $8 \%$ of students included a male and a female or a neutral figure in their drawing. $60 \%$ of students at the private university drew a female figure (which corresponds to the percentage of female students); while $83 \%$ of students at the public university drew a male figure (Figure 1).

Perceiving science related fields as male-dominated arenas is the stereotypical image among the general population across borders ${ }^{19}$, including Latin American countries ${ }^{16,20}$. In the particular case of engineering, recent studies based on the DAE test have shown that the male-dominated stereotype is the predominant view held by P-12 United States ${ }^{3,4,9,13,17}$ as well as Mexican $^{1,2,12}$ students and teachers.

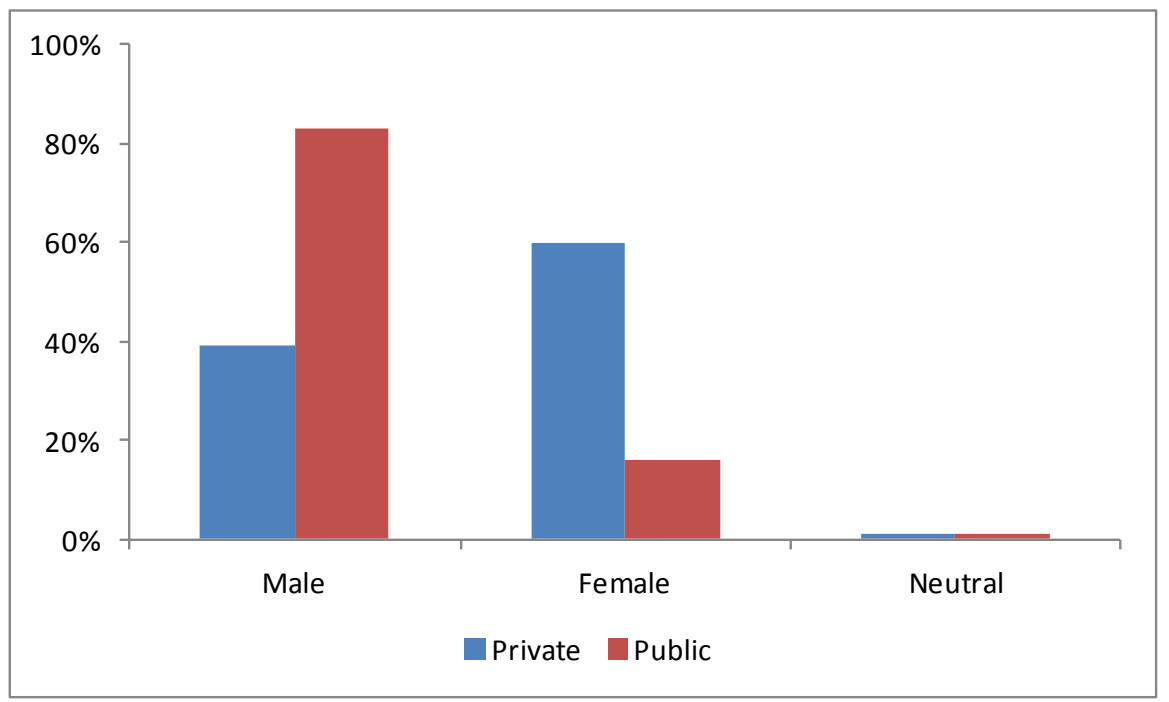

Figure 1. Distribution of gender in Puebla (private) and Tlaxcala (public) students' drawings of engineers.

Key elements that depicted engineers in action included drawings of engineers designing, supervising, directing, and being in charge of high-level responsibilities. Key elements that depicted characteristics of an engineer included drawings depicting engineers measuring, creating, being a leader, making decisions, using mathematics, using his/her intelligence, and wearing special cloths. Regarding work context, we identified four categories in the drawings: 
1. Engineers innovating. $58 \%$ of university students mention that his/her drawing refers to an engineer innovating, creating, or designing new technologies and formulas or making life easier throughout his/her actions.

2. Engineers in industry. $25 \%$ of participants refer to this category by describing that the engineer is doing some sort of activity in car, food, or chemical industry as well as general industrial activities.

3. Administration / supervision / direction. This category refers to the drawings in which the engineer is working in administration related duties, as well as supervision of projects in different companies and offices.

4. Research and development. Drawings that identify their engineer with the work of performing research, experiments, developing and designing artifacts, or working in food or chemical labs.

Related to work context, as can be seen in Figure 2:

1) $97 \%$ of drawings made by students in the public institution are related to engineers innovating something, while only $2 \%$ of students in the private school refer to the same category.

2) $81 \%$ of the drawings of students in a private institution are related to administration, supervision, and direction, while $19 \%$ of students in the public school refer to the same category.

3) Public school students made $63 \%$ of the drawings that classified an engineer in industry, whereas $37 \%$ of participants in the private institution refer to the same category.

4) The category research and development is referred to as the primary activity of engineers. Participants from the public university made $54 \%$ of these drawings while $46 \%$ corresponded to students in the private university.

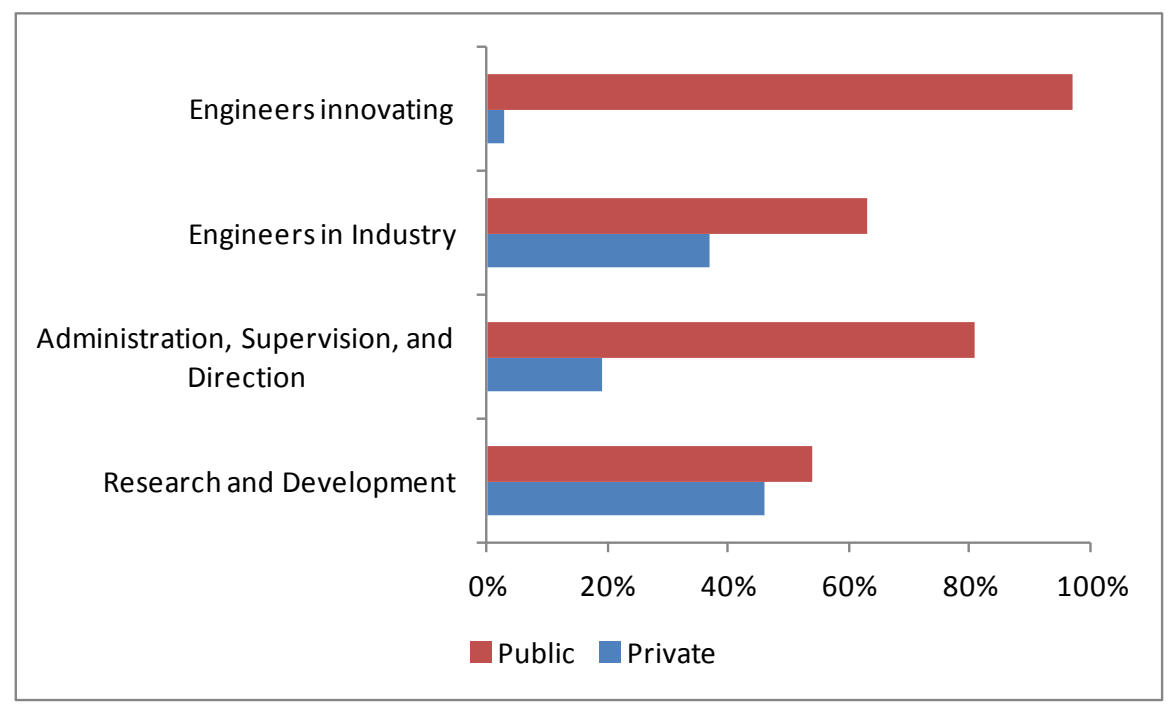

Figure 2. Distribution of images for the category "work context" in Puebla (private) and Tlaxcala (public) students' drawings of engineers. 
Fifty eight percent of the drawings depict engineers innovating technological devices (this category is of paramount importance to the study since it depicts a well-defined and correct conception about engineering and what an engineer does). In addition, $25 \%$ of the participants referred their drawings and answers to engineers working in the manufacturing industry (activity of greatest economical impact in central Mexico where Puebla and Tlaxcala are located), unlike previously reported studies ${ }^{1,2,12}$ from the southeast of Mexico where oilrelated activities were predominant (activity of greatest economical impact in that region). Thus, there is a clear influence of the cultural context on the image or perception that students have regarding engineers and engineering. It is essential to point out that in the southeast of Mexico, oil extraction is an activity of high economical impact; many companies have settled down in this area and most of the population if associated with this activity. On the other hand, in Puebla and Tlaxcala, general manufacturing and car industries have greater influence on the context of the population.

It is important to note that most of students' drawings attribute to their engineers a special type of clothing such as jumpsuits, helmets, boots, jeans and long sleeve shirts, special uniforms, safety glasses (goggles) and gloves, etc. (Figure 3). Interviews supported main findings while helping researchers gain insight into individual reasoning behind the 28 interviewed students' drawings and answers.

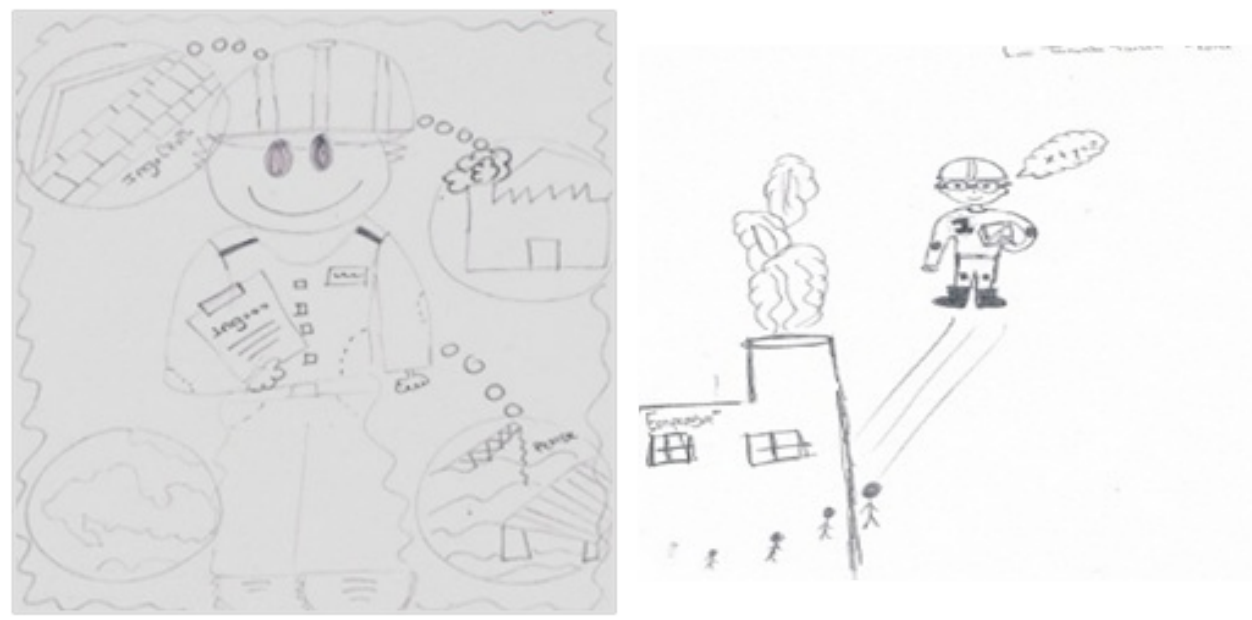

Figure 3. Drawings depicting an engineering directing (left), and an engineer working at industry (right).

Outcomes from this study confirm that cultural models to which humans are exposed can contribute significantly to their mental schema ${ }^{10}$. Teachers' ideas, knowledge and attitudes towards engineering and science influence students' perceptions, ideas, knowledge, as well as their attitudes toward engineering and science, thus perpetuating a wrong view ${ }^{21}$. Therefore, we are implementing a program to encourage engineering learning at the P-12 school levels, which consists of engineering teaching kits (ETKs), corresponding lesson plans, and professional development workshops in order to help teachers learn about engineering as well as implement the ETKs in their classrooms where their students are learning science and mathematics through guided inquiry, conceptual change, and engineering design ${ }^{12}$. Analysis 
of constructed responses indicates that some incoming engineering students held common misconceptions about engineers while several were knowledgeable about what engineers do. By taking these misconceptions into account, educational institutions can develop programs and adapt first-semester engineering curricula in order to form more accurate understandings of the role of the engineer and the engineering profession. Modifications to first-semester courses are underway at both studied institutions to help them in that regard.

The Draw an Engineer test used in this study proved to be a useful tool to identify Puebla and Tlaxcala incoming engineering students' perceptions about engineering and engineers as previous studies suggested for students and teachers ${ }^{1-6,9,12,17}$. Both studied settings provided a realistic image of engineering and engineers for their particular socioeconomic group. However, the particular characteristics of the study context, the sample size, and some limitations related to the instrument utilized to collect the data ${ }^{19}$, prevent us from making generalizations from our findings. In future studies, we will explore the suitability of the Draw an Engineer checklist $t^{22}$ and its flexibility to identify perceptions heavily based on a particular context; as well as the Engineering Identity Development Scale ${ }^{23}$ designed to assess students' identity development in engineering.

\section{Acknowledgments}

The Government of the State of Campeche and the National Council for Science and Technology (CONACyT) of Mexico are funding the project 2009-01-126164: Aprendiendo ciencia y matemáticas a través de la indagación dirigida, la reestructuración conceptual y el diseño en ingeniería en los salones de clase de los niveles básico y medio superior en Campeche. Authors Cruz López and Hernández Hernández gratefully acknowledge financial support for their PhD studies from Programa de Mejoramiento del Profesorado (PROMEP) of the Mexican Ministry of Public Education (SEP), Universidad Autónoma del Carmen, Universidad Juárez Autónoma de Tabasco, and Universidad Politécnica de Tlaxcala. We appreciate Puebla and Tlaxcala students' work and thoughtful critiques.

\section{Bibliography}

1. Carreño, S., Palou, E. and López-Malo, A. Eliciting P-12 Mexican teachers' images of engineering: What do engineers do? Proceedings of the ASEE Annual Conference and Exposition, Louisville, Kentucky, June 20-23, 2010.

2. Cruz López, C.C., Chavela Guerra, R.C., López-Malo, A. and Palou, E. Eliciting Mexican High School Students' Images of Engineering: What Do Engineers Do? Proceedings of the ASEE Annual Conference and Exposition, Vancouver, BC, Canada, June 26-29, 2011.

3. Knight, M. and Cunningham, C.M. Draw an engineer test (DAET): Development of a tool to investigate students' ideas about engineers and engineering. Proceedings of the ASEE Annual Conference and Exposition, Salt Lake City, Utah, June 20-23, 2004. 
4. Lyons, J. and Thomson, S. Investigating the long-term impact of an engineering-based GK-12 program on students' perceptions of engineering, Proceedings of the ASEE Annual Conference and Exposition, Chicago, Illinois, June 18-21, 2006.

5. Bodner, G., Karatas, F. and Micklos, M. Sixth grade students' images of engineering: what do engineers do? Proceedings of the ASEE Annual Conference and Exposition, Pittsburgh, Pennsylvania, June 22-25, 2008.

6. Ganesh, T.G., Thieken, J., Elser, M., Baker, D., Krause, S., Roberts, C., Kurpius-Robinson, S., Middleton, J. and Golden, J. Eliciting underserved middle-school youths' notions of engineers: draw an engineer, Proceedings of the ASEE Annual Conference and Exposition, Austin, Texas, June 14-17, 2009.

7. Diefes-Dux, H.A. and Capobianco, B.M. Work in progress: Interpreting elementary students' advanced conceptions of engineering from the Draw-an-Engineer Test. Proceedings of the Frontiers in Education Conference (FIE), Rapid City, South Dakota, October 12-15, 2011.

8. Weber, N., Duncan, D., Dyehouse, M., Strobel, J. and Diefes-Dux, H.A. The Development of a Systematic Coding System for Elementary Students' Drawings of Engineers. Journal of Pre-College Engineering Education Research, 1(1): 49-62, 2011.

9. Ganesh, T.G. Analyzing subject-produced drawings: The use of the Draw-an-Engineer assessment in context. Proceedings of the ASEE Annual Conference and Exposition, Vancouver, BC, Canada, June 26-29, 2011.

10. Gardner, H. Artful scribbles: The significance of children's drawings. New York: Basic Books, 1980.

11. OECD. Strong performers and successful reformers in education: Lessons from PISA for Mexico. Paris: Organisation for Economic Co-operation and Development, 2010.

12. Cruz López, C.C., Guillermo Echeverria, M.J., López-Malo, A. and Palou, E. Eliciting Yucatan Peninsula Teachers' Images of Engineering and Engineers. Proceedings of the 42nd ASEE/IEEE Frontiers in Education Conference. Seattle, Washington, October 3-6, 2012.

13. Cunningham, C.M., Lachapelle, C. and Lindgren-Streicher, A. Elementary teachers' understandings of engineering and technology. Proceedings of the ASEE Annual Conference and Exposition. Chicago, Illinois, June 2006.

14. Mead, M., Metraux, R. The image of the scientist among high school students: a pilot study. Science. 126: 384-390, 1957.

15. Chambers, D.W. Stereotype images of the scientist: The draw-a scientist test. Science Education. 67(2): 255-265, 1983.

16. Rodriguez Sala de Gomezgil, M.L. Mexican adolescents' image of the scientist. Soc. Stud. Sci. 5: 355-361, 1975.

17. Yap, C.C., Ebert, C. and Lyons, J. Assessing students' perceptions of the engineering profession. Proceedings South Carolina Educators for the Practical Use of Research Annual Conference. Columbia, South Carolina, 2003.

18. Oware, E., Capobianco, B. and Diefes-Dux, H.A. Gifted students' perceptions of engineers: A study of students in a summer outreach program. Proceedings of the ASEE Annual Conference and Exposition. Honolulu, Hawaii, June 2007.

19. Finson, K.D. Drawing a scientist: What we do and do not know after fifty years of drawings." School Science and Mathematics. 102(7): 335-345, 2002.

20. Medina-Jerez, W., Middleton, K.V. and Orihuela-Rabaza, W. Using the DAST-C to explore Colombian and Bolivian students' images of scientists [Electronic Version]. International Journal of Science and Mathematics Education. DOI: 10.1007/s10763-010-9218-3, 2011.

21. Lambert, M., Diefes-Dux, H.A., Beck, M., Duncan, D., Oware, E. and Nemeth, R. What is engineering? An exploration of P-6 grade teachers' perspectives. Proceedings of the 37th ASEE/IEEE Frontiers in Education Conference, Milwaukee, Wisconsin, October 2007.

22. Fralick, B., Kearn, J., Thompson, S. and Lyons, J. How middle schoolers draw engineers and scientists. Journal of Science Education and Technology. 18(1): 60-73, 2009.

23. Capobianco, B.M., French, B.F. and Diefes-Dux, H.A. Engineering Identity Development Among PreAdolescent Learners. Journal of Engineering Education. 101(4): 698-716, 2012. 